\title{
MEASURING ARTSE2017 Results from Wyoming and New York
}

\author{
Jennifer Fowler, Junhong Wang, Deborah Ross, Thomas Colligan, and Jaxen Godfrey
}

The Atmospheric Responses of 2017 Total Solar Eclipse (ARTSE2017) project was created to observe the response of the atmosphere to the shadow of the moon during a total solar eclipse using surface observations and radiosonde data.

D uring the 21 August 2017 total solar eclipse 20 collaborating institutions making up 10 teams undertook organization of comprehensive atmospheric observations. Total eclipses are rare and very impactful events, creating lifelong memories for those who witness them. Each century there are 50-70 total solar eclipses across the globe. The 2017 total solar eclipse marked the first of three that the continental United States will experience in the twenty-first century. The $\sim 100-\mathrm{km}$-wide band of totality took approximately an hour and a half to traverse the United States, starting in Oregon at 1020 Pacific daylight time (PDT) and ending in South Carolina at 1450 eastern daylight time (EDT) (see

AFFILIATIONS: FoWLER AND Ross-Montana Space Grant Consortium, Missoula, Montana; WANG-University at Albany, State University of New York, Albany, New York; Colligan-University of Montana, Missoula, Montana; GodfreY-Montana State University, Bozeman, Montana CORRESPONDING AUTHOR: Jennifer Fowler, jennifer.fowler@umontana.edu

The abstract for this article can be found in this issue, following the table of contents.

DOI:I0.II75/BAMS-D-I7-033I.I

In final form 4 February 2019

(C)2019 American Meteorological Society

For information regarding reuse of this content and general copyright information, consult the AMS Copyright Policy. www.greatamericaneclipse.com/nation/ for more information). A partial eclipse was visible from a much larger region covering most of continental United States with at least 0.7 magnitude. This national project, Atmospheric Responses of 2017 Total Solar Eclipse (ARTSE2017), was composed of two main phases: the field campaign for data collection on 21 August 2017 and the subsequent data analysis by teams from collaborating institutions performed over the following years. The purpose of this article is threefold: 1) to describe the ARTSE2017 project and the field campaign in Fort Laramie, Wyoming; 2) to show some preliminary results on the solar eclipse effects on the atmosphere using Wyoming (WY) and New York State Mesonet (NYSM) data; and 3) to inform BAMS readers about availability of this dataset to motivate future studies using this dataset and stimulate potential future research.

The effects of solar eclipses on Earth's atmosphere have been studied for past eclipses around the globe (Anderson et al. 1972; Eaton et al. 1997; Hanna 2000; Aplin and Harrison 2003; Ramchandran et al. 2002; Szalowski 2002; Amiridis et al. 2007; Founda et al. 2007; Giles and Hanna 2016). A comprehensive study revealed the meteorological impact of the 2015 U.K. solar eclipse across three countries (Giles and Hanna 2016). Total solar irradiance reaching the surface during eclipses is inversely proportional to the obscuration of the sun and is close to zero during totality 
(Founda et al. 2007). The surface temperature drops up to and beyond the midpoint of totality, with departures ranging from $2^{\circ}$ to $10^{\circ} \mathrm{C}$ from baseline. The changes in other meteorological variables were also reported before (Aplin and Harrison 2003; Anfossi et al. 2004). In contrast to the study of surface conditions, much less effort has been devoted to study the responses of the lowest layer of the atmosphere, the boundary layer (BL). This is partially due to lack of upper-air observations with high temporal resolution that capture the short lifetime of the eclipse. Sounding profiles of temperature, pressure, wind speed, and wind direction can indicate another potential atmospheric phenomenon generated during eclipses: tropospheric and stratospheric gravity (buoyancy) waves.

An attempt at obtaining these measurements was made during the 2015 U.K. solar eclipse studies by Marlton et al. (2016) that concluded, "it is impossible to deduce whether the eclipse generated any gravity waves...Further work might concentrate on making similar observations during a future solar eclipse. In particular, the solar eclipse of 21 August 2017 across the USA offers greater potential for detecting eclipseinduced gravity waves, because it will occur in the summer months at lower latitudes." In summary, the 2017 total solar eclipse was a perfect opportunity for such a study.

\section{ECLIPSE MEASUREMENTS WYOMING SITE WITH 3 SYSTEMS}

○ Central site North site

- South site

\begin{tabular}{|l|c|c|c|c|c|c|}
\hline & $\begin{array}{c}\mathbf{5} \text { min } \\
\text { Before 1 } \\
\text { Contact }\end{array}$ & $\begin{array}{c}\mathbf{4 0} \text { min } \\
\text { Before } \\
\text { Totality }\end{array}$ & $\begin{array}{c}\mathbf{5} \text { min } \\
\text { Before } \\
\text { Totality }\end{array}$ & $\begin{array}{c}\text { 30 min } \\
\text { After } \\
\text { Totality }\end{array}$ & 8/22/17 \\
\hline $\begin{array}{l}6 \text { hrly }(8 / 20 \\
11: 46-8 / 21\end{array}$ & & & & & \\
Central & $5: 46)$ & S3_30m & S3_20m & S3_20m & S3_burst & 11:46am \\
\hline North & $11: 46 \mathrm{am}$ & S2_30m & S2_20m & S2_burst & S2_burst & \\
\hline South & $11: 46 \mathrm{am}$ & S1_30m & S1_20m & S1_burst & S1_burst & \\
\hline
\end{tabular}

$\mathrm{C} 1=10: 24: 01, \mathrm{C} 2=11: 45: 04, \mathrm{~T}=11: 46: 18, \mathrm{C} 3=11: 47: 32, \mathrm{C} 4=13: 12: 12 \mathrm{MDT}$

20m: $6 \mathrm{~km}$ and 30m: $9 \mathrm{~km}$ with 15 minutes between launches

FIG. I. Observing strategy at the Wyoming site including three radiosonde sites and the launch schedule. In the table, $S$ and the subsequent one-digit number denote the radiosonde system. The balloon flight duration in minutes (abbreviated " $m$ ") is given after the underscore. The duration of the flight in minutes is correlated to approximate maximum altitude in kilometers below the table.
FIELD PROJECT AND DATA COLLECTION. Wyoming field campaign. Fort Laramie was selected as our central site because it was close to the center of the path of totality and had campsites with amenities available to host 40 participants for the field campaign. In addition, Fort Laramie has historically low cloud levels in August, with cloud fraction the smallest from July to September $(<30 \%)$ and ranging from $21 \%$ to $39 \%$ in August from 2002 to 2016, creating ideal conditions for eclipse observations. ARTSE2017 deployed three radiosonde systems and surface sensors around Fort Laramie. The three sites were named north, center, and south, with the north site in Lusk, Wyoming, the center site in Fort Laramie, and the south site approximately 4 miles west of Yoder, Wyoming (Fig. 1). Totality across central Wyoming occurred from 1130 to 1200 mountain daylight time (MDT). Graw DFM09 radiosondes measuring upper-air temperature, relative humidity, pressure, wind speed, and wind direction at a vertical resolution of about $5 \mathrm{~m}$ were released from the central location and the two subsites along the edge of totality to understand cross-eclipse track variations (Fig. 1). Coordinated sets of launches were made before, during, and after totality at all three sites. In addition, radiosonde launches every $6 \mathrm{~h}$ were made at the central site from 1146 to 1146 MDT 22 August 2017. The launch locations and schedule shown in Fig. 1 were designed to collect data in a fashion that facilitated the comparison of meteorological conditions before, during, and after the eclipse. All of the flights were led by undergraduates and were successfully implemented within two minutes of the proposed launch schedule. Temporal resolution and flight termination altitudes of the radiosonde campaign were planned to focus on boundary layer measurements in accordance with the overarching goals of the national campaign. The national experimental spatial design was based on the standard mesonet spacing of $1-40 \mathrm{~km}$. Driving the 
national campaign were some of the following core questions and objectives:

- What is the magnitude of the temperature drop at the surface and in the boundary layer and troposphere? How much time lag [time from totality to the time when minimum (or maximum) values are recorded] is there between the temperature minimum and minimum in solar flux? At which altitude(s) is the temperature variation the largest?

- How do temperature reductions and BL heights vary across the path of totality? Is the response fairly uniform or do asymmetries arise? How far into the penumbral zone do detectable temperature variations extend?

- How does surface temperature vary within the spatial domain of the path of totality, on fine scales, given variations in land surface cover (grass, cropland, forest, bare soil, urban surface, water)?

- What is the response of the surface wind field within the path of totality? Is the kinematic response instantaneous or time lagged to the thermal response?

- How are the findings above for the 2017 eclipse compared to that for prior events?

Atmospheric gravity waves were a secondary focus and multiple radiosonde flights were added to the schedule to collect necessary datasets in an attempt to answer the question of whether eclipseinduced stratospheric gravity waves can be detected with radiosonde data. Gravity wave studies help address another question of interest: namely, does the cooling and subsequent rewarming signal exhibit vertical propagation?

In addition to the radiosonde launches, we had five large-balloon $(2,000-5,000 \mathrm{~g})$ launches. Four of the five balloons carried video payloads to capture the eclipse from the edge of space and two of the large balloons carried scientific instruments focused on student projects. One highlight from these large balloon launches is the Loki Lego Launcher team. Video and science results from their launch can be seen on their website (https://lokilegolauncher .wordpress.com/). Surface data collection at the center site started on 1000 MDT 19 August and continued until 0641 MDT 22 August, Aug 2017 over $68 \mathrm{~h}$ of observations. The ARTSE2017 team used a Lufft WS502-UMB surface station to record temperature, relative humidity, pressure, wind speed, wind direction, and solar irradiance values every $2 \mathrm{~s}$.

All instruments were carefully tested and calibrated in advance to ensure their accuracy. This testing and calibration was a major focus for 10 -week undergraduate student summer internships funded by the Montana Space Grant Consortium and for a high school teacher under the M.J. Murdock Charitable Trust Partners in Science Program. Significant products from these efforts include a standard operating procedure (SOP) for radiosonde flights as well as undergraduate training materials and exercises for students from nonatmospheric-science-related fields.

Scientific endeavors such as this are most successful when shared with the broader scientific community as well as with the general population. Acting on that belief we had a designated team deployed at Glendo State Park, Wyoming, with education and outreach activities related to the total solar eclipse. At our central radiosonde field site we also engaged in education and outreach activities such as nighttime star parties, science presentations, solar telescope viewings, and launch observations of both the large and radiosonde balloon payloads (Fig. 2).

New York State Mesonet. One distinctiveness of ARTSE2017 was to make use of existing operational statewide mesonets including Missouri and Kentucky mesonets on the path of the totality, and NYSM on the $70 \%-80 \%$ eclipse path. The newly established,

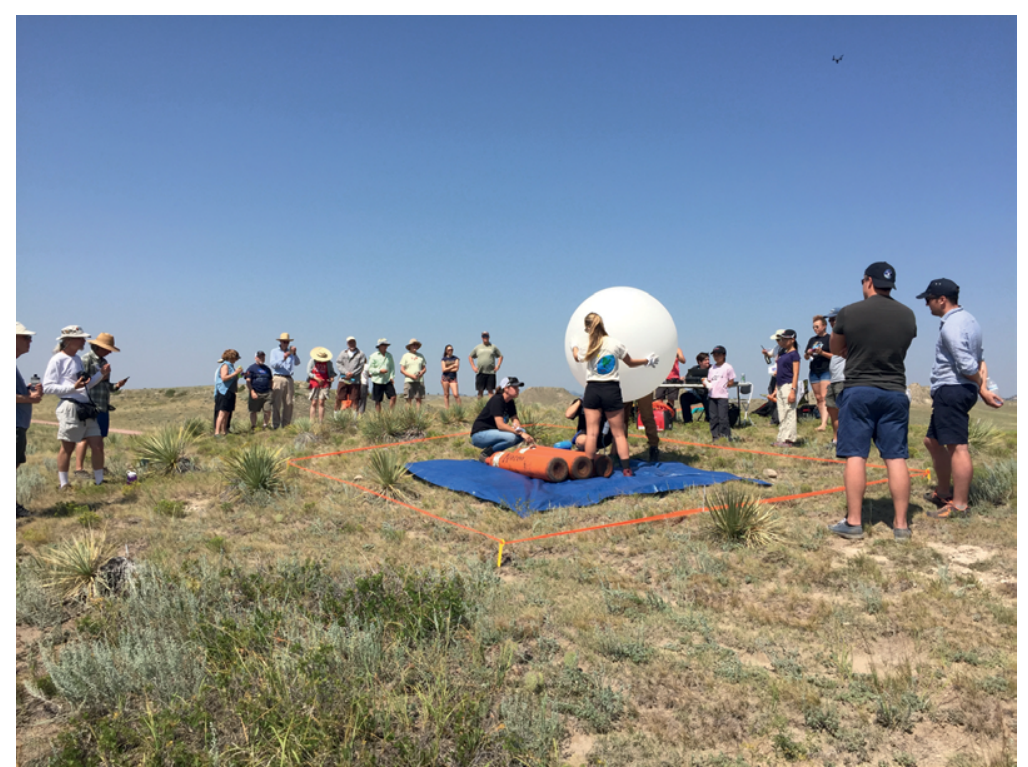

FIG. 2. Center site radiosonde launch with public observers on $\mathbf{2 0}$ 
state-of-the-art NYSM has raw data available at 3-s intervals and consists of 126 stations across New York State (NYS) (see Fig. 9). All stations report 5-min measurements of standard meteorological variables (surface temperature, relative humidity, and pressure) plus snow depth, total solar radiation, soil moisture, and temperature at three levels. The measurements include images from cameras installed in the stations, and are reported at 5-min intervals 24/7. On 21 August 2017, 124 of 126 sites were installed and operational. In addition, the NYSM has three subnetworks (profiler, flux, and snow) composed of 17, 17, and 20 sites to provide atmospheric vertical profiles, the surface energy budget, and snow water equivalent, respectively. The NYSM surface and atmospheric data are all useful to monitor the reactions of the atmosphere to the eclipse in the $70 \%-80 \%$ totality range. NYSM data enable one to look at mesoscale conditions before, during, and after the eclipse and isolate the eclipse impact on the mesoscale, especially whether it alters mesoscale circulation. Previous studies have used data from meteorological networks (Clark 2016; Gray and Harrison 2016; Hanna et al. 2016) to study the surface responses to solar eclipses. Additional variables from NYSM, including soil parameters, profiling data, and camera images and the nature of complex terrain and various topography in NYS provided an unprecedented opportunity to study the eclipse impact. Only results from preliminary analysis of NYSM data are shown here that address our objectives of the extent of detectable

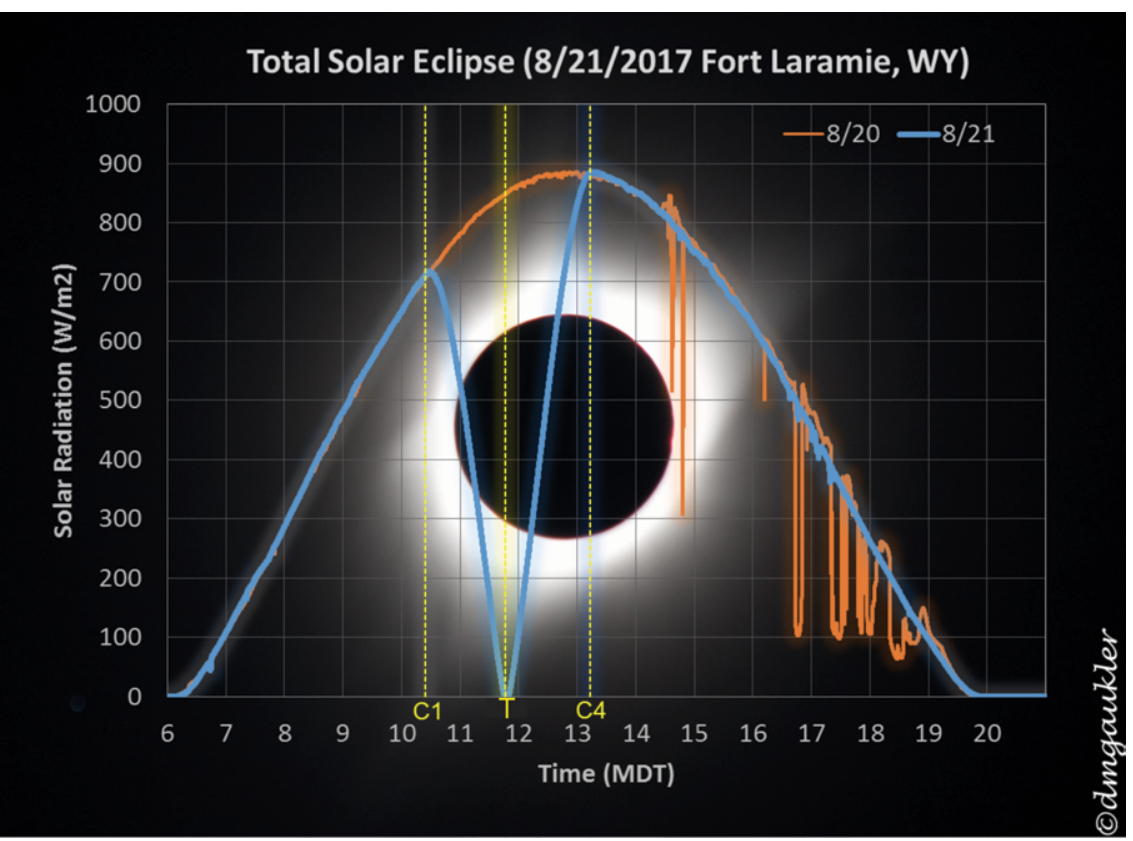

Fig. 3. Time series of total solar radiation $\left(\mathrm{W} \mathrm{m}^{-2}\right)$ on 20 and 21 Aug 2017 at Fort Laramie. The vertical lines CI, T (totality), and C4 mark the times of first contact, totality, and fourth contact, respectively. temperature variations into the penumbral zone as well as surface temperature variations given variations in land surface cover.

\section{SCIENTIFIC HIGHLIGHTS AND PRELIMI-} NARY RESULTS. Surface responses. There are five stages during a total solar eclipse. First contact $(\mathrm{C} 1)$ is the first moment that the moon is visible against the sun, second contact (C2) is the beginning of totality, totality $(\mathrm{T})$ is when the moon's disk completely covers the sun, third contact (C3) is the end of totality, and fourth contact (C4) represents the end of the moon covering any part of the solar disk. The timing of radiosonde flights during this campaign were aligned with these five stages. The eclipse in Wyoming lasted $2 \mathrm{~h} 12 \mathrm{~min} 11 \mathrm{~s}$ from 1024:41 to 1313:27 MDT with totality lasting $2 \mathrm{~min} 19 \mathrm{~s}$ from $1146: 11$ to 1148:30 MDT. The time series of total solar radiation measured by the Lufft WS502-UMB surface station's pyranometer is shown in Fig. 3. Total solar radiation on 21 August started to decrease at first contact and dropped to $0 \mathrm{~W} \mathrm{~m}^{-2}$ from 1145:30 MDT until 1149:40 $\mathrm{MDT}$, when it began recovering. The maximum solar radiation loss was $850 \mathrm{~W} \mathrm{~m}^{-2}$ during totality (Fig. 3). This is within the range of previous studies.

General atmospheric conditions on 21 August in Fort Laramie provided almost perfect conditions for observing the total solar eclipse. The high temperature for the day was $27.8^{\circ} \mathrm{C}$ and the lowest temperature recorded was $13.5^{\circ} \mathrm{C}$. Mean relative humidity was $48 \%$ and no precipitation fell. Mean wind speed was $4.2 \mathrm{~m} \mathrm{~s}^{-1}$ with gusts to $11.8 \mathrm{~m} \mathrm{~s}^{-1}$ with an average visibility of 8 miles. Clearsky conditions prevailed with some clouds appearing between 1400 and 1500 MDT and after 1600 MDT (visible from the solar radiation curve on Fig. 3). A high pressure system sat over the region after a weak low pressure front had passed the evening prior. Conditions on 21 August included moderate midlevel airflow aloft and conditional instability seen in the lapse rates (Fig. 6).

The responses of surface temperature and wind speed to the eclipse in 
Wyoming are shown in Figs. 4 and 5, respectively. Surface temperatures started to drop at 1036:20 MDT, corresponding to $\mathrm{C} 1$, and reached the local minimum at $1201 \mathrm{MDT}$ (about $10 \mathrm{~min}$ after totality) with a total temperature drop of $3.5^{\circ} \mathrm{C}$ (Fig. 4). The temperature decrease is well within the range of previous studies although the time lag is approximately $5 \mathrm{~min}$ faster than the normal range of 15-30 min. This could be due to land surface cover. More analysis into this phenomenon nationally is yet to be done and comparison within the three Wyoming sites is hindered by the lack of identical surface station equipment at all three Wyoming sites across the path. During the eclipse, the wind speed also dropped, with an average decrease of $2.7 \mathrm{~m} \mathrm{~s}^{-1}$ (Fig. 5). Wind speed reached a minimum about 25 min after totality, as seen in Fig. 5. The time lag for wind speed is within the range of previous studies but the magnitude exceeds the 2015 eclipse across the British Isles (Gray and Harrison 2016).

To document human and animal responses, we had volunteers participating in studies on how life responds to the eclipse that correlated with our data. Observations were made in conjunction with

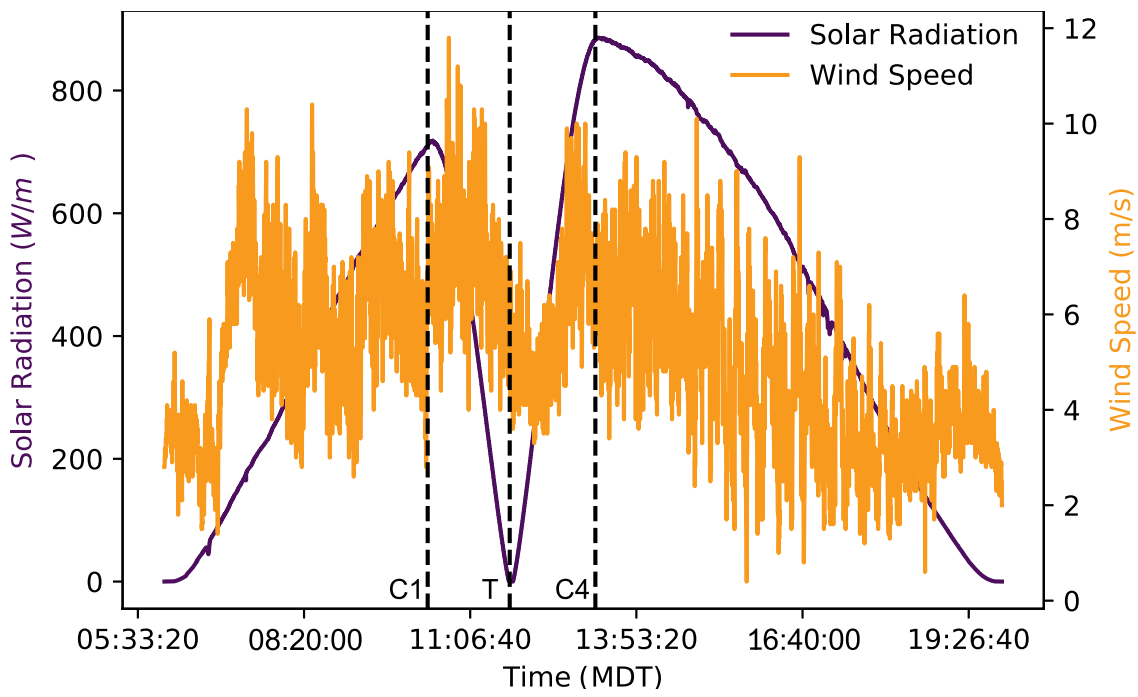

Fig. 5. Time series of total solar radiation $\left(\mathrm{W} \mathrm{m}^{-2}\right)$ and surface wind speed $\left(\mathrm{m} \mathrm{s}^{-1}\right)$ on 21 Aug 2017 at Fort Laramie. The vertical lines $\mathrm{Cl}, \mathrm{T}$, and $\mathrm{C} 4$ mark the times of first contact, totality, and fourth contact, respectively.
iNaturalist's "Life Responds: Total Solar Eclipse 2017" (www.inaturalist.org/). Birds began to sing and feed as the temperature dropped with the appearance of eclipse "twilight" and returned to shade as temperatures increased after totality. The impact on the ARTSE2017 team was profound, with a respectful silence falling as totality began and triumphant cheering at the moment of totality.

Boundary layer response. Comparing lapse rates during the eclipse within the BL, we see gradual cooling from 1019 MDT before the first contact with the coldest profile after totality at $1216 \mathrm{MDT}$ and strong surfacelayer cooling in the " $40 \mathrm{~min}$ before" and " $5 \mathrm{~min}$ before" soundings (Fig. 6). The coldest profile occurs about 15 min after totality (“ $5 \mathrm{~min}$ before totality/GE" line in Fig. 6), displaying a longer time lag (by about $5 \mathrm{~min}$ ) in temperature compared to the minimum measured solar flux than the time lag measured directly at the surface for temperature. With limited previous studies involving radiosonde profiles available for comparison coupled with the age of some articles such as Randhawa et al. (1970), it is difficult to draw reasonable 
conclusions about whether our measurements fall within some normal range particularly when having to consider differences in measurement techniques and sensor biases. However, the time-lag differences motivate the potential to investigate vertical propagation of atmospheric gravity waves starting at the surface due to the cooling and subsequent rewarming signal. This phenomenon is further explored in the "Stratospheric gravity wave signatures" section.

In literature searches limited measurements of boundary layer height using radiosondes exist. During the 2006 eclipse over Greece a change in the boundary layer of approximately $175 \mathrm{~m}$ was measured with radiosondes (Amiridis et al. 2007). For the 2015 eclipse over the British Isles authors Gray and Harrison state there is observational evidence from a radiosonde of boundary layer height change but the data are not shown (Gray and Harrison 2016). At the 2017 Wyoming site totality was observed to impact the BL height dramatically, though not as substantially as the alteration in height due to the transition from day to night (diurnal cycle) which we also measured for comparison of magnitude of the eclipse change. The Richardson method was used to calculate BL height (Seidel et al. 2012):

$$
\mathrm{Ri}_{z}=\frac{\left(\frac{g}{\theta_{v s}}\right)\left(\theta_{v z}-\theta_{v s}\right)\left(z-z_{s}\right)}{\left(u_{z}-u_{s}\right)^{2}+\left(v_{z}-v_{s}\right)^{2}+\left(b u_{*}^{2}\right)},
$$

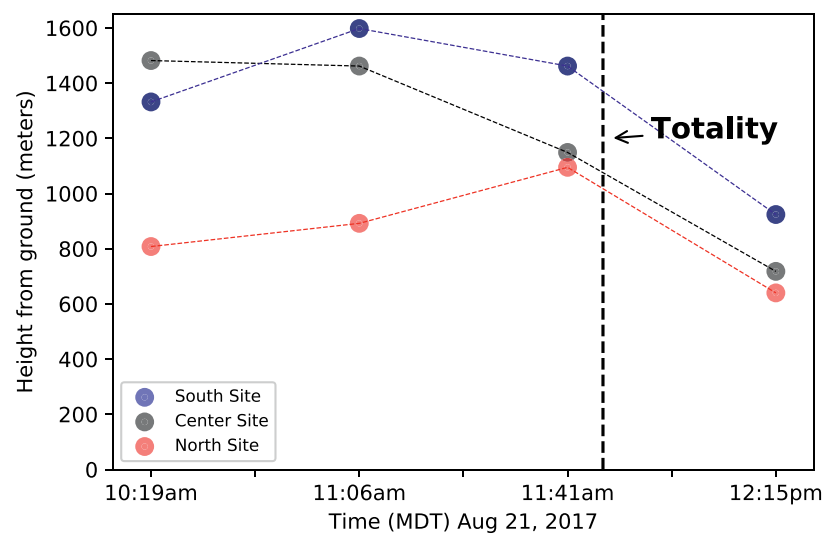

where $z$ is altitude (m) above ground level (AGL), $g$ is acceleration due to gravity $\left(\mathrm{m} \mathrm{s}^{-2}\right), \theta_{v}$ is virtual potential temperature $\left({ }^{\circ} \mathrm{C}\right), u$ and $v$ are wind components $\left(\mathrm{m} \mathrm{s}^{-1}\right), b$ is a constant assumed to be zero, and $u_{\star}$ is the surface friction velocity $\left(\mathrm{m} \mathrm{s}^{-1}\right)$. Figure 7 shows the fluctuation in BL height at each site across the path for the duration of the eclipse in the left panel, thus addressing how BL height changes within the spatial domain of the path of totality. The right panel gives a visual comparison between the change in magnitude of a typical diurnal cycle in contrast to the effect on the BL from the eclipse. The BL heights prior to first contact were rising, as expected in a normal diurnal cycle. North and south sites continued this rise longer than at the central site, then the south and central sites began to see a

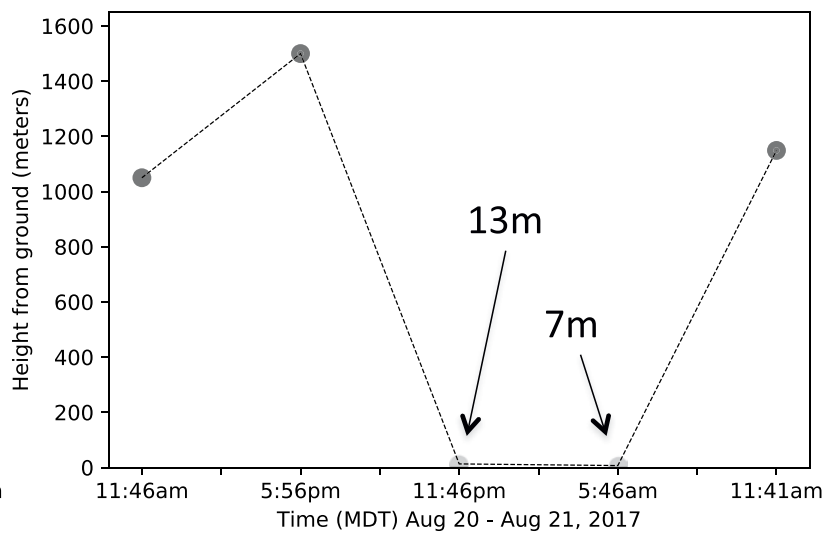

FIG. 7. (left) BL height comparisons from radiosonde launches during the eclipse on $2 I$ Aug at three launch sites and (right) the diurnal cycle from 20 to 21 Aug 2017 at the central site. Having the two graphs side by side gives a visual comparison between the change in magnitude of a typical diurnal cycle and the effect on the $B L$ from the eclipse. The bulk Richardson number method was used to derive the BL height. 
decrease in BL height between the first and second contacts, while the north site did not see a decrease until just prior to totality. All three sites showed a sharp decline in BL height through the third contact. The dramatic decrease in BL height was due to the temperature change throughout the atmosphere during totality (Fig. 6). Total change in BL height for the 24-h period encompassing 20-21 August was approximately $1400 \mathrm{~m}$ at the center site, and the total change in BL height between pre- and posteclipse on 21 August was $500 \mathrm{~m}$ at the center site (Fig. 7). More analysis is needed to assess the differences between Wyoming sites with the north site experiencing a total BL height between pre- and posteclipse of approximately $400 \mathrm{~m}$ and the south site of approximately $600 \mathrm{~m}$. All our sites show a more significant change during the eclipse than radiosonde data from the 2006 eclipse while the values for 2017 are equivalent to wind profiler measurements made during the 2015 eclipse that measured a difference of $400 \mathrm{~m}$ (Gray and Harrison 2016). In the future, making additional radiosonde measurements of $\mathrm{BL}$ heights across the eclipse path diurnally could help identify spatial and land-cover differences by using the diurnal change as a benchmark.

Stratospheric gravity wave signatures. An additional phenomenon of interest during a solar eclipse are atmospheric gravity waves. These waves are phenomena arising from a multitude of sources and are transverse waves that propagate in all directions through the atmosphere as an important transport mechanism for momentum and energy. Their detection, characterization, and subsequent parameterization is important for input into global climate models. Solar eclipses can generate these wave phenomena (Zhang et al. 2017), but as of yet, solar eclipse-induced gravity waves' existence has not been definitively detected in the lower atmosphere, specifically the troposphere and stratosphere (Aplin et al. 2016). The elliptically polarized waves from the surface due to the eclipse are expected to have a strong propagation signature outwards from totality, not unlike bow waves formed from a ship traveling through water.

Chimonas and Hines (1970) first predicted the existence of eclipse-driven waves in 1970, and until the 21 August 2017 solar eclipse evidence of their existence was not conclusive. Researchers at the Massachusetts Institute of Technology's Haystack observatory have deduced the presence of these waves in the ionosphere (Zhang et al. 2017) but have not implied the waves were generated from the surface as expected in detecting eclipse-induced gravity waves in the stratosphere and troposphere. As such, the radiosonde data collected by the ARTSE2017 field campaign were analyzed for evidence of stratospheric waves. The data analysis focused on identifying gravity wave signals present after the eclipse that were not present before the eclipse. The horizontal propagation direction was then compared to expectations. If a wave was present after the eclipse and traveling away from the shadow, it was marked as a possible eclipsedriven gravity wave.

The linear theory of gravity waves allows for the horizontal propagation direction and intrinsic frequency of the wave to be determined directly from the major-axis orientation and axial ratio of the polarization ellipse, respectively. To detect the waves in radiosonde profiles, we first apply a wavelet transform using the method described in (Torrence and Compo 1998). The transform used a Morlet basis function to effectively filter out unwanted frequencies from the radiosonde data (Zink and Vincent 2001).

After performing the wavelet transform on the zonal $(u)$ and meridional $(v)$ components of the wind, we sum their absolute values in quadrature and are left with a power surface, denoted by

$$
S=\left|W_{u}\right|^{2}+\left|W_{v}\right|^{2}
$$

A contour plot is shown in Fig. 8. After creating the contour plot, the surface is scanned for maxima. After a maximum $S_{\max }$ is detected, the surface is scanned until its value reaches (3/4) $S_{\max }$. After the extent of the maxima is determined, the inverse transformation is applied. Ellipses are then fit to the data, and parameters are recorded, using the axial ratio and major-axis orientation. The power surface in Fig. 8a shows at least four potential waves, their presence indicated by bright yellow. Over the extent of the campaign approximately 40 waves were detected.

Some wave signals that were not present before the eclipse appeared in the data after the eclipse. Comparing contour plots from before the eclipse, Fig. 8b, and the contour plot after the eclipse, Fig. 8a, the difference is clearly seen. Focusing on the wave detected around $22.5 \mathrm{~km}$ in altitude with a 600 -s period in Fig. 8a, a large spectral peak is present in the data gathered after the eclipse that was not present before the eclipse (Fig. 8b). Although many waves detected after the eclipse had a propagation direction of approximately between $\pm 90^{\circ}$ relative to north as expected of bow waves, the distributions of 
these wave parameters before and after the eclipse were not distinct enough to conclusively identify the eclipse as a source of these waves. For example, many of our detected wave periods were longer than anticipated. Detecting eclipse-driven gravity waves was difficult due to the termination of radiosonde profiles prior to $10 \mathrm{~km}$, in accordance with the national campaign's focus on boundary layer effects. During and after the eclipse, 12 flights were terminated before reaching the troposphere, leading to gaps in essential data that reduced the detection probability of eclipse-generated waves. If stratospheric eclipse-generated gravity waves are the main field campaign objective detection probability would be enhanced with increased temporal resolution prior to the eclipse. Such a field campaign should be considered with the upcoming 2019 and 2020 South American solar eclipses as well as the 2024 North American eclipse. The South American eclipses present a unique opportunity to correlate data with ionospheric measurements to track eclipse-driven gravity waves throughout the entire atmosphere.

Preliminary results from NYSM. The partial eclipse arrived at the furthest west NYS station (Clymer, New York) at $1310 \mathrm{EDT}$, peaked around $1430 \mathrm{EDT}$, and left NYS at around 1600 EDT. It lasted about $2 \mathrm{~h} 30 \mathrm{~min}$ and had magnitudes (fraction of the sun's diameter covered by the moon) ranging from 0.674 to 0.8 at 122 NYSM stations. The impact of the solar eclipse in NYS depended on many factors, such as the eclipse magnitude, cloud conditions, timing, synoptic situation, and surrounding environment. Only some preliminary results are summarized here.

We used 5-min NYSM solar radiation, temperatures at 2 and $9 \mathrm{~m}$, and wind gust data on $21 \mathrm{Au}-$ gust 2017 to calculate a few variables. They include minimum solar radiation, 
(a) Srad_min (W/m2) 08/21/2017

mean $=195.4$

$\mathrm{SD}=43.21$

$\mathrm{R}=-0.02$

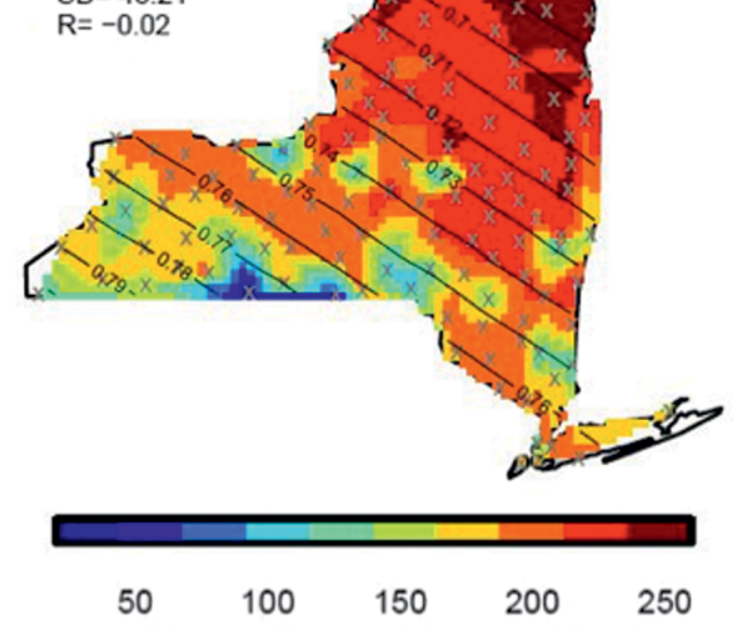

(c) T drops (C) 08/21/2017

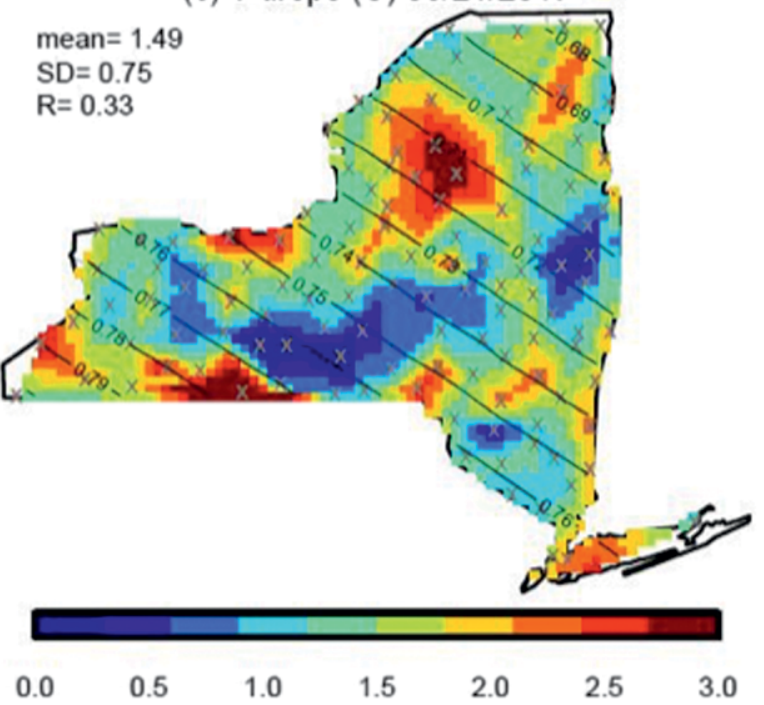

(b) Srad drops (W/m2) 08/21/2017

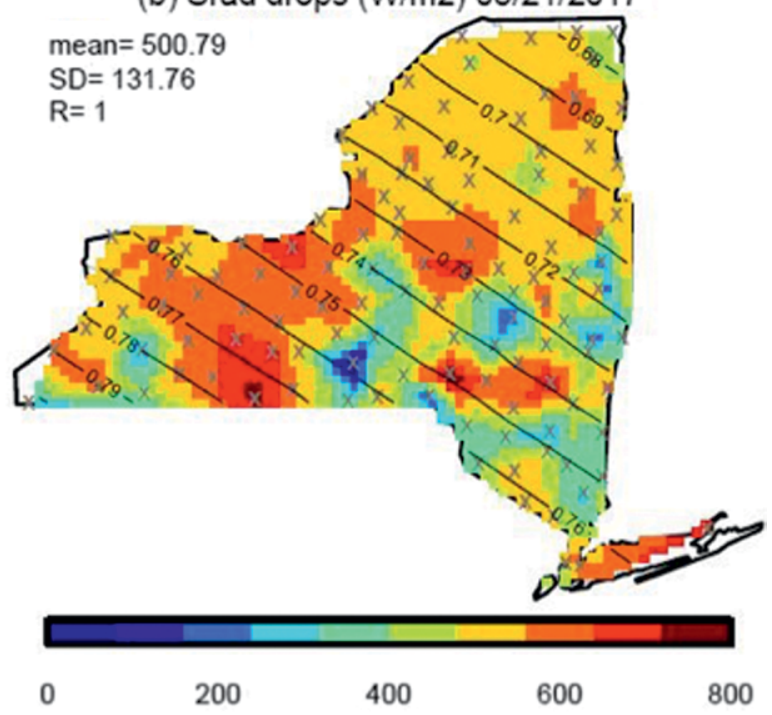

(d) T9m-T2m increases (C) $08 / 21 / 2017$ mean $=0.63$ $\mathrm{SD}=0.26$ $\mathrm{R}=0.45$

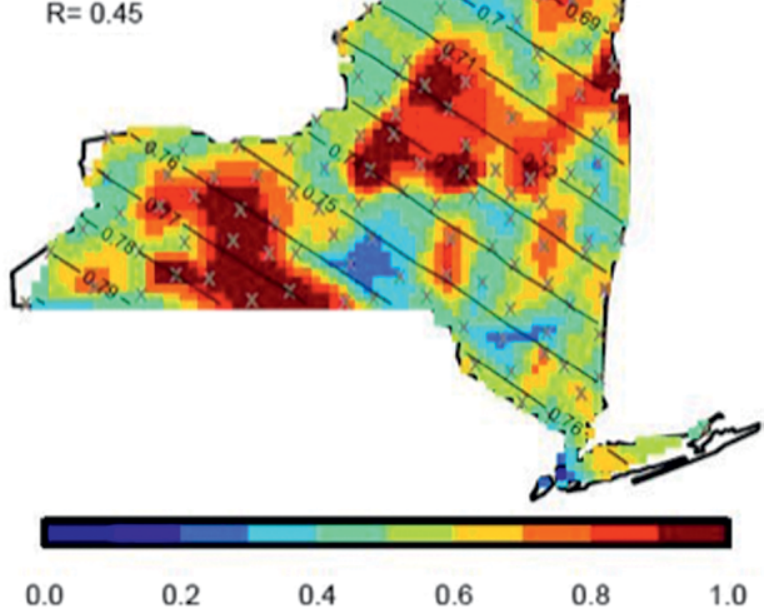

FIG. 9. (a) Total solar radiation $\left(\mathrm{W} \mathrm{m}^{-2}\right)$ at the maximum eclipse, drops of (b) solar radiation and (c) surface air temperature $\left({ }^{\circ} \mathrm{C}\right)$ at $2 \mathrm{~m}$, and (d) increases of temperature differences between 9 and $2 \mathrm{~m}$ using NYSM data on 21 Aug 2017. The values for mean, standard deviation (SD), and correlation $R$ with solar radiation drops are given in the legends. Black contour lines are eclipse magnitudes, and gray $\times$ symbols denote the station locations. See text for more details.

temperature at $2 \mathrm{~m}$, and wind gusts at the maximum eclipse (T) or afterward, and their drops from $\mathrm{C} 1$. The temperature difference between 9 and $2 \mathrm{~m}$ is also calculated along with its increase from $\mathrm{C} 1$ to its maximum value after totality. In addition, the time from totality to the time when minimum (or maximum) values are recorded is also calculated and referred as to the "time lag." Figures 9 and 10 show maps and time series of those variables, respectively. For Fig. 9, the station data are interpolated to a regular grid for color filling. At totality, all sites experienced a daytime minimum solar radiation (Fig. 10a). Figure 9a shows that the minimum solar radiation follows the eclipse magnitude contour lines and increases diagonally from west to east. Except at a few stations the minimum solar radiation is very low (cold color areas in Fig. 9a) as a result of overcast conditions. The largest solar radiation drops occurred in the western NYS mainly due to relatively clear skies at $\mathrm{C} 1$ and larger eclipse magnitude, but the east plateau and Hudson valley have smaller drops as a result of cloudy conditions at $\mathrm{C} 1$ (Fig. 9b). The shadow of the moon resulted in cooling the surface by a mean of $1.49^{\circ} \pm 0.75^{\circ} \mathrm{C}$, and 
the minimum temperature lagged totality by about 13 min (Fig. 10b), which is consistent with that in WY (Fig. 4) and the findings from the 2015 U.K. eclipse (Hanna et al. 2016). In addition, the surface layer denoted by the temperature difference between 9 and $2 \mathrm{~m}$ also behaved like a nighttime inversion layer during the eclipse and show increases at all stations (Fig. 9d), and the increase has the best correlation (0.45) with the solar radiation drops and occurred only a few minutes after totality (Figs. $9 \mathrm{~d}$ and 10c). This suggests that the surface layer responded to the eclipse much faster and was more sensitive to the moon shadow than directly at the surface. The radiosonde data at the WY central site also show larger cooling at the first radiosonde data point (about $6 \mathrm{~m}$ above the ground) than at the surface (Fig. 6). The surface wind gusts also slowed down by an average of $2.68 \pm 1.09 \mathrm{~m} \mathrm{~s}^{-1}$ at about $22 \mathrm{~min}$ after totality (Fig. 10d), which is again consistent with the findings from the WY site (Fig. 5).

(a) 2017 Solar Eclipse (8/21/2017 NYSM)

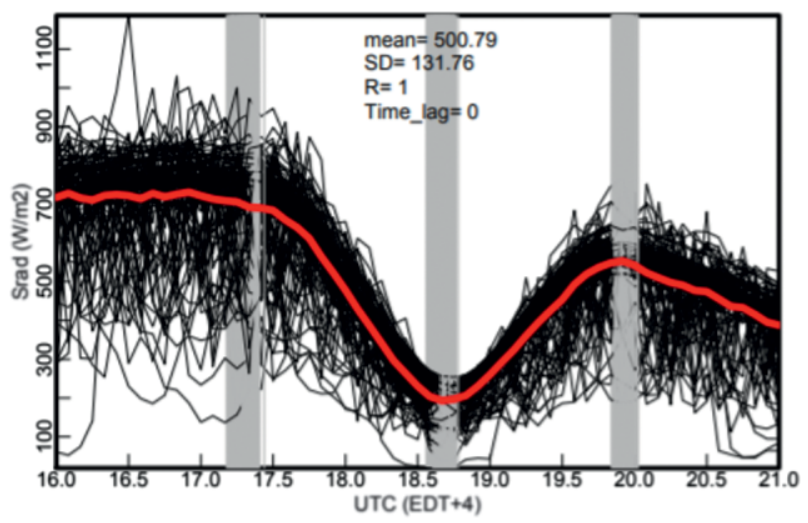

(c) 2017 Solar Eclipse (8/21/2017 NYSM)

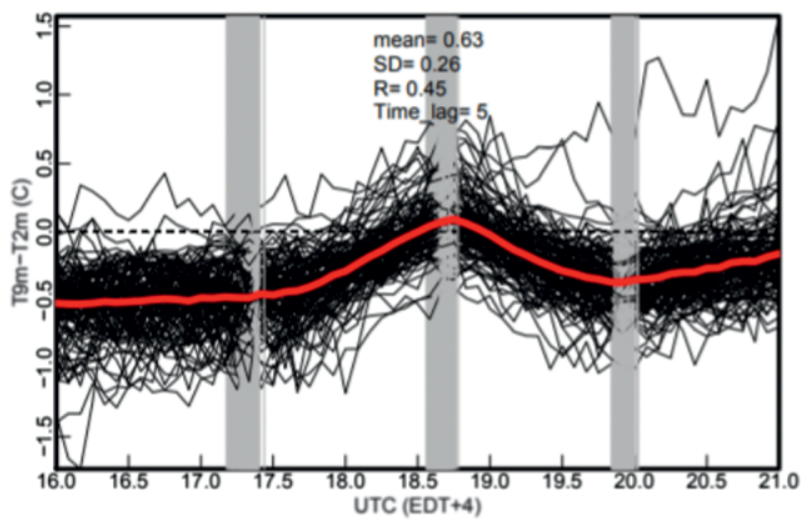

EDUCATIONAL HIGHLIGHTS. The word "pipeline" has become cliché. Perhaps a better term is conduit. As such we need dedicated mentors to support and direct students through their K-20 careers. This includes channeling students to the next mentor. One example of a research area that encompasses such an opportunity over this large educational range is balloonborne experiments. These experiments cover fields from physics, chemistry, biology, environmental science, geoscience, atmospheric science, mechanical engineering, electrical engineering, and computer science. Within each field, ballooning represents its own conduit from theoretical research to field work to data analysis. It is a basis for group project work as well as individual assignments. It is also a unique opportunity to leverage education, research, and workforce development. Teams of students at all levels can and have been trained in proper data gathering techniques that can be used by researchers in the public sector as well as companies in the private sector. The field campaign

(b) 2017 Solar Eclipse (8/21/2017 NYSM)

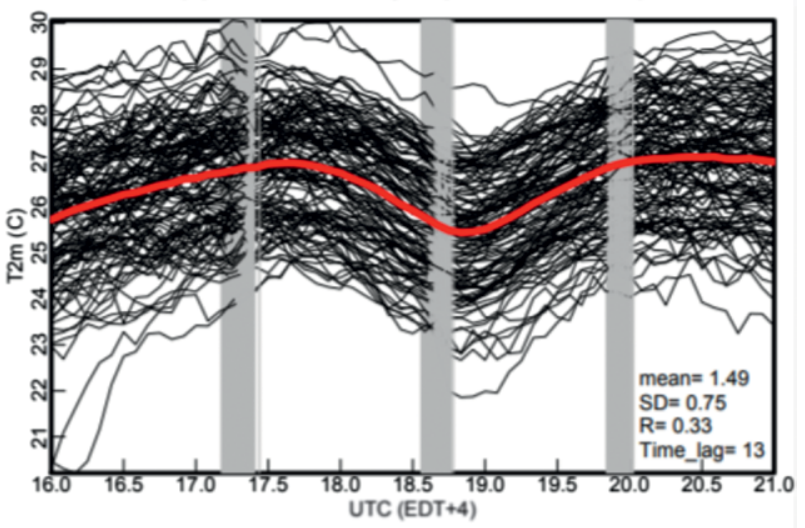

(d) 2017 Solar Eclipse (8/21/2017 NYSM)

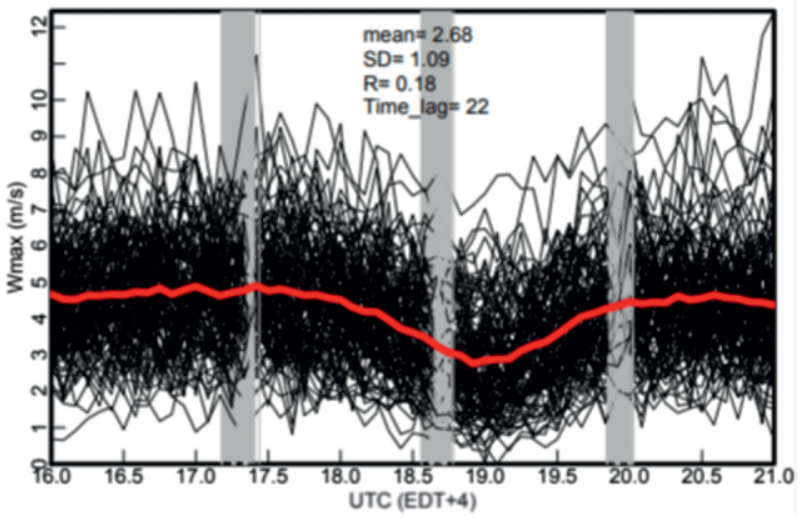

FIG. 10. Thin black lines show time series of (a) total solar radiation, (b) surface air temperature at $2 \mathrm{~m}$, (c) temperature difference between 9 and $2 \mathrm{~m}$, and (d) wind gusts from 1600 UTC (I200 EDT) to 2100 UTC (I700 EDT) 2 I Aug 2017 from all I22 NYSM stations. Red thick lines show the average of all stations. Three groups of vertical gray lines show the times of first contact, maximum eclipse, and fourth contact from left to right, respectively. The values for mean, standard deviation (SD), and correlation $R$ with solar radiation drops and the mean lag time (min) are given in the legends. See the text for more details. 
and the subsequent analysis of data are evidence of the effectiveness of the training ballooning can provide.

The Wyoming team consisted of faculty, staff, and undergraduate students from institutions of higher education, including one tribal college, as well as two high school students, two middle school students, and one high school teacher. Only one faculty and undergraduate student have formal training in atmospheric sciences. Dedicated training and team building over two years was needed to accomplish the field campaign in meeting launch schedules and data quality. Interspersed within the launch training was work on data analysis techniques and programming of algorithms for individual projects. All this preparation was necessary for availability of a quality dataset to motivate future studies using the dataset and stimulate potential future expansion. As mentioned earlier, the most fundamental tool from the preparation was a developed standard operating procedure as well as training protocols.

In addition to the direct team participants we relied heavily on volunteers for logistics such as food, beverages, and photographic documentation. Without these dedicated volunteers the team would have been easily distracted with day-to-day needs during the field campaign. Funding was a challenge during the entire preparation of the field campaign and subsequent analysis period. Due to the educational nature of the campaign we were able to leverage funding from Montana Space Grant Consortium, New York Space Grant Consortium, New York State Mesonet, NORIS Group GmbH-Graw Radiosondes, National Weather Service Upper Air Program, M.J. Murdock Charitable Trust Partner's in Science Program, Miles Community College, and Chief Dull Knife College. These institutions range from private sector to federal, state, and local entities. This gave all the students experience with a cooperative funding model.

CONCLUSIONS. A review of the scientific literature reveals a very limited number of studies on effects of solar eclipses on the atmosphere worldwide. However, the few documented effects have been wideranging, with atmospheric thermal changes being most prominent, from the boundary layer upward through the ionosphere. There have been more observed variations in the surface-level wind, solar radiation, and temperature. There is a transient yet substantial set of responses in the thermal and kinematic atmospheric fields that develop at a much more rapid rate compared with the normal diurnal cycle. The data collected in ARTSE2017 and NYSM add to the current body of work toward understanding short-term weather phenomena and serves to address the complex nature of particular phenomena such as gravity waves. Eclipse-driven stratospheric gravity waves have not been definitively measured in past eclipses and this study begins to highlight the need for continued field campaigns designed specifically to address this phenomenon. In the future coordinating both lower- and upper-atmospheric measurements can lead to a holistic understanding of the entire atmospheric structure and effects of eclipses on this structure. With our boundary layer and surface temperature measurements we can investigate the nature of the underlying surface (grass, bare soil, water) that seems to influence the magnitude of the observed temperature drop. Preliminary NYSM data analysis reveals similar responses of surface meteorological variables in a spatially and temporally coherent fashion between partial and total eclipses. Expanding our analysis to include additional datasets from sites along the path of totality with varying surface types and more mesonet data are of future interest.

We found key components of success to this field campaign to be planning, organization, and extensive training. The standard operating procedure (SOP) developed for this campaign was of critical importance to obtaining the data needed for both boundary layer effects and gravity wave measurements. The SOP had input from experts in atmospheric science, radiosonde manufacturers, and participating students. Both the structure of this field campaign as recorded in the SOP and the data collected will be available for future training and scientific research. Thus we have trained the next generation workforce while engaging the public, gaining additional scientific resources and new collaborations for future field campaigns related to high-impact events.

ACKNOWLEDGMENTS. We appreciate the support from NWS Upper Air Program, Graw Radiosonde Company, Montana Space Grant Consortium, New York Space Grant Consortium, M.J. Murdock Charitable Trust Partner's in Science Program, Miles Community College, Chief Dull Knife College, Montana State University, and University of Montana. Initial training and coordination was graciously provided by Dr. Robert Pasken at Saint Louis University. National campaign goals were developed by the national eclipse radiosonde committee: Jennifer Fowler, Juhong Wang, Robert Pasken, Sen Chiao at San Jose State University, and Jeffrey Halverson at University of Maryland, Baltimore County. This research was also made possible by the New York State Mesonet (NYSM). Original funding for NYSM was provided by Federal Emergency Management Agency Grant FEMA4085-DR-NY, with the continued support of the NYS 
Division of Homeland Security and Emergency Services; the state of New York; the Research Foundation for the State University of New York (SUNY); the University at Albany, SUNY; the Atmospheric Sciences Research Center at SUNY Albany; and the Department of Atmospheric and Environmental Sciences at SUNY Albany. Python wavelet software provided by Evgeniya Predybaylo is based on Torrence and Compo (1998) and is available online (http://atoc.colorado.edu/research/wavelets/).

\section{REFERENCES}

Amiridis, V., and Coauthors, 2007: Aerosol lidar observations and model calculations of the planetary boundary layer evolution over Greece, during the March 2006 total solar eclipse. Atmos. Chem. Phys., 7, 6181-6189, https://doi.org/10.5194/acp-7-6181-2007.

Anderson, R. C., D. R. Keefer, and O. E. Myers, 1972: Atmospheric pressure and temperature changes during the 7 March 1970 solar eclipse. J. Atmos. Sci., 29, 583-587, https://doi.org/10.1175/1520 -0469(1972)029<0583:APATCD>2.0.CO;2.

Anfossi, D., G. Schayes, G. Degrazia, and A. Goulart, 2004: Atmospheric turbulence decay during the solar total eclipse of 11 August 1999. Bound.Layer Meteor., 111, 301-311, https://doi.org/10.1023 /B:BOUN.0000016491.28111.43.

Aplin, K. L., and R. Harrison, 2003: Meteorological effects of the eclipse of 11 August 1999 in cloudy and clear conditions. Proc. Roy. Soc. London, 459A, 353-371, https://doi.org/10.1098/rspa.2002.1042.

_ , C. J. Scott, and S. L. Gray, 2016: Atmospheric changes from solar eclipses. Philos. Trans. Roy. Soc., 374A, 20150217, https://doi.org/10.1098/rsta.2015 .0217 .

Chimonas, G., and C. Hines, 1970: Atmospheric gravity waves induced by a solar eclipse. J. Geophys. Res., 75, 875, https://doi.org/10.1029/JA075i004p00875.

Clark, M., 2016: On the variability of near-surface screen temperature anomalies in the 20 March 2015 solar eclipse. Philos. Trans. Roy. Soc., 374A, 20150213, https://doi.org/10.1098/rsta.2015.0213.

Eaton, F., J. Hines, W. Hatch, R. Cionco, J. Byers, D. Garvey, and D. Miller, 1997: Solar eclipse effects observed in the planetary boundary layer over a desert. Bound.-Layer Meteor., 83, 331-346, https:// doi.org/10.1023/A:1000219210055.

Founda, D., D. Melas, S. Lykoudis, I. Lisaridis, E. Gerasopoulos, G. Kouvarakis, M. Petrakis, and C. Zerefos, 2007: The effect of the total solar eclipse of 29 March 2006 on meteorological variables in Greece. Atmos. Chem. Phys., 7, 5543-5553, https:// doi.org/10.5194/acp-7-5543-2007.
Giles, H. R., and E. Hanna, 2016: The solar eclipse: A natural meteorological experiment. Philos. Trans. Roy. Soc., 374A, 20150225, https://doi.org/10.1098/rsta.2015.0225.

Gray, S. L., and R. G. Harrison, 2016: Eclipse-induced wind changes over the British Isles on the 20 March 2015. Philos. Trans. Roy. Soc., 374A, 20150224, https:// doi.org/10.1098/rsta.2015.0224.

Hanna, E., 2000: Meteorological effects of the solar eclipse of 11 August 1999. Weather, 55, 430-446, https://doi.org/10.1002/j.1477-8696.2000.tb06481.x.

— , and Coauthors, 2016: Meteorological effects of the solar eclipse of 20 March 2015: Analysis of UK Met Office automatic weather station data and comparison with automatic weather station data from the Faroes and Iceland. Philos. Trans. Roy. Soc., 374A, 20150212, https://doi.org/10.1098/rsta.2015.0212.

Marlton, G. J., P. D. Williams, and K. A. Nicoll, 2016: On the detection and attribution of gravity waves generated by the 20 March 2015 solar eclipse. Philos. Trans. Roy. Soc., 374A, 20150222, https://doi.org/10.1098 /rsta.2015.0222.

Ramchandran, P., R. Ramchandran, K. Gupta, S. Patil, and P. Jadhav, 2002: Atmospheric surface-layer processes during the total solar eclipse of 11 August 1999. Bound.-Layer Meteor., 104, 445-461, https:// doi.org/10.1023/A:1016577306546.

Randhawa, J. S., B. H. Williams, and M. D. Kays, 1970: Meteorological influence of a solar eclipse on the stratosphere. U.S. Army Electronics Command Research and Develpoment Tech. Rep. ECOM-5345, 59 pp.

Seidel, D., Y. Zhang, A. Beljaars, J. Golaz, A. Jacobson, and B. Medeiros, 2012: Climatology of the planetary boundary layer over the continental United States and Europe. J. Geophys. Res., 117, D17106, https:// doi.org/10.1029/2012JD018143.

Szalowski, K., 2002: The effect of the solar eclipse on air temperature and near the ground. J. Atmos. Sol.-Terr. Phys., 64, 1589-1600, https://doi.org/10.1016/S1364 $-6826(02) 00134-7$.

Torrence, C., and G. P. Compo, 1998: A practical guide to wavelet analysis. Bull. Amer. Meteor. Soc., 79, 61-78, https://doi.org/10.1175/1520-0477(1998)079<0061:AP GTWA $>2.0 . \mathrm{CO} ; 2$.

Zhang, S., P. Erickson, L. Goncharenko, A. Coster, W. Rideout, and J. Vierinen, 2017: Ionospheric bow waves and perturbations induced by the 21 August 2017 solar eclipse. Geophys. Res. Lett., 44, $12067-$ 12073, https://doi.org/10.1002/2017GL076054.

Zink, F., and R. Vincent, 2001: Wavelet analysis of stratospheric gravity wave packets over Macquarie Island: 2. Intermittency and mean-flow accelerations. J. Geophys. Res., 106, $10289-10297$, https://doi .org/10.1029/2000JD900846. 